\title{
Cecília Meireles
}

Maria Aparecida Baccega

Livre-docente aposentada da USP, professora de pós-graduação da ECA-USP e da ESPM-SP, editora dos Cadernos de Pesquisa da ESPM-SP, coordenadora adjunta do Núcleo de Pesquisa Comunicação e Práticas de Consumo - ESPM-SP.

E-mail: mabga@usp.br

... Liberdade, essa palavra que o sonho humano alimenta que não há ninguém que explique e ninguém que não entenda...

Cecília Meireles, Romanceiro da Inconfidência

Filha de Carlos Alberto de Carvalho Meireles, funcionário do Banco do Brasil, e de Matilde Benevides Meireles, professora, Cecília Benevides de Carvalho Meireles nasceu em 7 de novembro de 1901, no Rio de Janeiro. Não chegou a conhecer o pai, que morreu três meses antes de ela nascer. Ainda não tinha três anos completos quando perdeu a mãe. Foi criada pela avó.

Concluiu o curso primário em 1910, ocasião em que recebeu de Olavo Bilac, inspetor escolar do Rio de Janeiro, medalha de ouro por ter feito todo o curso com "distinção e louvor". Durante sua vida inteira falou do orgulho de ter recebido essa medalha. Terminou o curso normal no Instituto de Educação do Rio de Janeiro em 1917. Exerceu o magistério nas escolas públicas do então Distrito Federal. Publicou seu primeiro livro de poesias, Espectro, em 1919.

Casou-se com o pintor português Fernando Correia Dias em 1922, com quem teve três filhas: Maria Elvira, Maria Mathilde e Maria Fernanda (artista teatral). Em 1935, seu marido suicidou-se; em 1940, ela se casou com o professor e engenheiro agrônomo Heitor Vinícius da Silveira Grilo.

De 1930 a 1931, escreveu diariamente textos sobre problemas de educação no Diário de Notícias. Organizou a primeira biblioteca infantil do Rio de Janeiro em 1934. Aposentou-se em 1951 como diretora de escola, porém continuou a trabalhar no Rádio Ministério da Educação, no Rio de Janeiro, como produtora e redatora de programas culturais.

Recebeu vários prêmios, entre os quais destacamos: Prêmio de Tradução/Teatro, da Associação Paulista de Críticos de Arte, em 1962; Prêmio Jabuti de Tradução de Obra

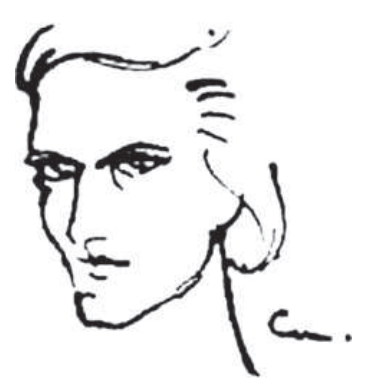

Cecília Meireles - Autoretrato Literária, pelo livro Poemas de Israel, em 1963, e Prêmio Jabuti de Poesia, pelo livro Solombra, em 1964, ambos concedidos pela Câmara Brasileira do Livro.

Traduziu peças teatrais de Federico Garcia Lorca, Rabindranath Tagore, Rainer Rilke e Virginia Woolf.

Faleceu no Rio de Janeiro a 9 de novembro de 1964, e teve seu corpo 
velado no Ministério da Educação e Cultura.

Postumamente, em 1965, a Academia Brasileira de Letras outorgou-lhe o Prêmio Machado de Assis pelo conjunto de sua obra.

A grande poetisa recebeu várias homenagens públicas ao longo dos anos: Biblioteca Infanto-Juvenil Cecília Meireles (Alto da Lapa, SP); Escola Municipal de Primeiro Grau Cecília Meireles (Cangaíba, SP); Escola Municipal de Educação Infantil Cecília Meireles (São Mateus, SP); Sala Cecília Meireles, um grande salão de concertos e conferências (Largo da Lapa, RJ). É nome de rua no bairro Jardim Japão em São Paulo e em São Domingos de Benfica, nos arredores de Lisboa; em Ponta Delgada, capital do arquipélago dos Açores, há uma avenida com o nome da escritora, que era neta de açoreanos. Em 1989, uma cédula de cem cruzados novos com sua efígie foi lançada pelo Banco Central do Brasil, no Rio de Janeiro.

O Governo Federal, por decreto, instituiu 2001 como "O Ano da Literatura Brasileira", em comemoração ao sesquicentenário de nascimento do escritor Silvio Romero e ao centenário de nascimento de Cecília Meireles, Murilo Mendes e José Lins do Rego.

Sua poesia, traduzida para o espanhol, francês, italiano, inglês, alemão, húngaro, hindu e urdu, e musicada por Alceu Bocchino, Luis Cosme, Letícia Figueiredo, Ênio Freitas, Camargo Guarnieri, Francisco Mingnone, Lamartine Babo, Bacharat, Norman Frazer, Ernest Widma e Fagner, foi assim julgada pelo crítico Paulo Rónai: "Considero o lirismo de Cecília Meireles o mais elevado da moderna poesia de língua portuguesa. Nenhum outro poeta iguala o seu desprendimento, a sua fluidez, o seu poder transfigurador, a sua simplicidade e seu preciosismo, porque Cecília, só ela, se acerca da nossa poesia primitiva e do nosso lirismo espontâneo... A poesia de Cecília Meireles é uma das mais puras, belas e válidas manifestações da literatura contemporânea”.

\section{BIBLIOGRAFIA $^{1}$}

Espectros, em 1919; Criança, meu amor, 1923; Nunca mais... e Poemas dos poemas, 1923; Criança meu amor..., 1924; Baladas para El-Rei, 1925; O espírito vitorioso, 1929 (ensaio, Portugal); Saudação à menina de Portugal, 1930; Batuque, samba e macumba, 1935 (ensaio, Portugal); A festa das letras, 1937; Viagem, 1939; Vaga música, 1942; Mar absoluto, 1945; Rute e Alberto, 1945; Rui: pequena história de uma grande vida, 1949 (biografia de Rui Barbosa para crianças); Retrato natural, 1949; Problemas de literatura infantil, 1950; Amor em Leonoreta, 1952; Doze noturnos de Holanda \& O aeronauta, 1952; Romanceiro da inconfidência (uma de suas obras mais importantes, que serviu de base ao filme Os Inconfidentes, de Joaquim Pedro de Andrade), 1953; Batuque, 1953; Pequeno oratório de Santa Clara, 1955; Pistóia, Cemitério Militar Brasileiro, 1955; Panorama folclórico de Açores, 1955; Canções, 1956; Giroflê, giroflá, 1956; Romance de Santa Cecília, 1957; A Bíblia na literatura brasileira, 1957; A rosa,

1. Disponível em: <http:// www.releituras.com/cmeireles bio.asp>. Acesso em: $1 \overline{5}$ set. 2005 . 1957; Obra poética, 1958; Metal Rosicler, 1960; Poemas escritos na Índia, 1961; Poemas de Israel, 1963; Antologia poética, 1963; Solombra, 1963; Ou isto ou aquilo, 1964; Escolha o seu sonho, 1964; Crônica trovada da cidade de Sam Sebastiam no quarto centenário 
da sua fundação pelo capitam-mor Estácio de Saa, 1965; O menino atrasado, 1966; Poésie (versão para o francês de Gisele Slensinger Tydel), 1967; Antologia poética, 1968; Poemas italianos, 1968; Poesias ("Ou isto ou aquilo" \& inéditos), 1969; Flor de poemas, 1972; Poesias completas, 1973; Elegias, 1974; Flores e canções, 1979; Poesia completa, 1994; Obra em prosa (6 vols.), 1998; Canção da tarde no campo, 2001.

Os poemas transcritos foram retirados de $\mathrm{Ou}$ isto ou aquilo ${ }^{2}$.

\section{AS DUAS VELHINHAS}

Duas velhinhas muito bonitas,

Mariana e Marina,

Estão sentadas na varanda:

Marina e Mariana.

Elas usam batas de fitas,

Mariana e Marina.

E penteado de tranças:

Marina e Mariana.

Tomam chocolate, as velhinhas,

Mariana e Marina.

Em xícaras de porcelana,

Marina e Mariana.

Uma diz: "Como a tarde é linda, não é, Marina?"

A outra diz: "Como as ondas dançam,

não é, Mariana?"

"Ontem, eu era pequenina",

diz Marina.

"Ontem, nós éramos crianças",

diz Mariana.

E levam à boca as xicrinhas,

Mariana e Marina,

As xicrinhas de porcelana:

Marina e Mariana.

Tomam chocolate, as velhinhas,

Mariana e Marina.

E falam de suas lembranças,

Marina e Mariana.

\section{O MENINO AZUL}

$\mathrm{O}$ menino quer um burrinho

para passear.

Um burrinho manso,

que não corra nem pule,

mas que saiba conversar.

$\mathrm{O}$ menino quer um burrinho

que saiba dizer

o nome dos rios,

das montanhas, das flores,

- de tudo o que aparecer.

$\mathrm{O}$ menino quer um burrinho

que saiba inventar

histórias bonitas

com pessoas e bichos

e com barquinhos no mar.

E os dois sairão pelo mundo

que é como um jardim

apenas mais largo

e talvez mais comprido

e que não tenha fim.

(Quem souber de um burrinho desses,

pode escrever

para a Rua das Casas,

Número das Portas,

ao Menino Azul que não sabe ler.)
2. Rio de Janeiro: Civilização Brasileira; Brasília: INL, 1977. 
comunicação \& educação • Ano XI • Número 1 • jan/abr 2006

\section{TANTA TINTA}

Ah! menina tonta, toda suja de tinta mal o sol desponta!

(Sentou-se na ponte, muito desatenta... E agora se espanta: Quem é que a ponte pinta com tanta tinta?...)

A ponte aponta e se desaponta. A tontinha tenta limpar a tinta, ponto por ponto e pinta por pinta...

Ah! a menina tonta! Não viu a tinta da ponte!

\section{A BAILARINA}

Esta menina

tão pequenina

quer ser bailarina.

Não conhece nem dó nem ré mas sabe ficar na ponta do pé.

Não conhece nem mi nem fá mas inclina o corpo para cá e para lá.

Não conhece nem lá nem si, mas fecha os olhos e sorri.

Roda, roda, roda com os bracinhos no ar e não fica tonta nem sai do lugar.

Põe no cabelo uma estrela e um véu e diz que caiu do céu.

Esta menina tão pequenina quer ser bailarina.

Mas depois esquece todas as danças, e também quer dormir como as outras crianças. 


\section{AS MENINAS}

Arabela

abria a janela.

Carolina

erguia a cortina.

E Maria

olhava e sorria:

"Bom dia!"

Arabela

foi sempre a mais bela.

Carolina;

a mais sábia menina.

E Maria

apenas sorria:

FIGURINHAS

"Bom dia!"

Pensaremos em cada menina

que vivia naquela janela;

uma que se chamava Arabela,

I

No claro jardim

A menina chora

pela borboleta

que se foi embora.

outra que se chamou Carolina.

Mas a nossa profunda saudade

é Maria, Maria, Maria,

que dizia com voz de amizade:

"Bom dia!"

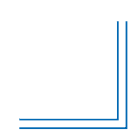

Ora, ora, ora,

Não chore tanto!

Nossa Senhora!

A menina chora

no claro jardim

um choro sem fim.

Nem o céu azul

é bonito, agora,

pois a borboleta já

se foi embora.

Não chore tanto!

Nossa Senhora!

Que choro sem fim

a menina chora

no claro jardim. 
comunicação \& educação • Ano XI • Número 1 • jan/abr 2006

II

Ora, ora, ora!

Onde está meu quintal amarelo e encarnado, com meninos brincando de chicote-queimado, com cigarras nos troncos e formigas no chão, e muitas conchas brancas dentro da minha mão?

E Júlia e Maria

e Amélia onde estão?

Onde está meu anel e o banquinho quadrado, e o sabiá na mangueira e o gato no telhado?

- e a moringa de barro, e o cheiro do alvo pão? e tua voz, Pedrina, sobre o meu coração? Em que altos balanços se balançarão?... 